\title{
PEREKONOMIAN PARIWISATA ISLAMI TERHADAP PEDAGANG DI KAWASAN MAKAM SUNAN
}

\author{
KALIJAGA 11 \\ Galih Caesario Rahman \\ Mahasiswa Program Studi S1 Ekonomi Islam-Fakultas Ekonomi dan Bisnis Universitas \\ Airlangga \\ Email: galih-ca-r-11@feb.unair.ac.id \\ Sunan Fanani \\ Departemen Ekonomi Syariah- Fakultas Ekonomi dan Bisnis-Universitas Airlangga \\ Email: sunan-f@feb.unair.ac.id
}

\begin{abstract}
This study aims to figure how is the dynamic or economic condition change caused by the existence of Islamic tourism of Sunan Kalijaga Tomb to stall sellers who most of them are the locals lives around the Islamic tourism of Sunan Kalijaga tomb.

The research method used is descriptive case study method. Where the data collection done by interview and observation. In this research, the informant is the parties involved in the tourism activity, which is the seller, the visitor, and the worker around the Islamic tourism of Sunan Kalijaga tomb, Demak District. The data analysis used is data reduction, data presentation, and make a conclusion.

The research result suggests that the existence of Islamic tourism of Sunan Kalijaga tomb Demak District brings economical change towards the seller works around.
\end{abstract}

Keywords: Islamic Tourism, Tourism Economic, Income

I.PENDAHULUAN

Pengelolaan

pariwisata

merupakan kegiatan yang kompleks

melibatkan banyak sektor yaitu

pemerintah, stakeholder, serta

masyarakat. Pariwisata saat ini

merupakan salah satu sektor industri yang

berkembang sangat pesat, hal ini

dikarenakan pariwisata menjadi sektor pendukung perekonomian secara global.

Potensi terhadap pasar untuk

pengembangan wisata Islami (muslim) jika

dilihat dari populasi muslim di dunia sebanyak 1,8 milyar atau sekitar $28 \%$ dari total populasi dunia sebesar 6,4 miliar yang tersebar di 148 negara. Dari total muslim di dunia, $62 \%$ berasal dari AsiaPasifik atau dengan jumlah 972 juta jiwa (www.tempo.com).
Pariwisata syariah atau pariwisata islami menurut sofyan (2012:54) adalah pariwisata yang mencakup semua jenis pariwisata, dimana ditanamkan nilai-nilai Islam. Sebagai Negara yang memiliki umat muslim terbanyak didunia, Indonesia menjadi banyak rujukan beberapa umat islam Negara sekitar untuk berkunjung ke tempat-tempat sejarah seperti makam wali songo masjid serta pesantren.

Pada sektor industri pariwisata di Indonesia, Jawa Tengah merupakan salah satu tujuan wisata. Pertumbuhan wisatawan ke Jawa Tengah beberapa tahun ini mengalami peningkatan.

Hasil tabel 1.1 menunjukkan jumlah kunjungan wisatawan ke jawa tengah pada tahun 2014 sebanyak 20.271.679 orang dan pada tahun 2015 sebanyak

1) Jurnal ini merupakan bagian dari skripsi dari Galih Caesario Rahman, NIM : 041114110 
Rahman, et al/Jurnal Ekonomi Syariah Teori dan Terapan Vol. 5 No. 6 Juni 2018: 511-521; PEREKONOMIAN PARIWISATA ISLAMI TERHADAP PEDAGANG DI KAWASAN MAKAM SUNAN

\section{KALIJAGA}

33.452.079 orang. Hal ini membuktikan bahwa selama dua tahun kunjungan wisatawan ke Jawa Tengah mengalami peningkatan sebesar60,3\%. Kekayaan, keindahan serta pesona budaya merupakan salah satu daya tarik utama pariwisata provinsi Jawa Tengah.

Tabel 1.1

Jumlah kunjungan wisatawan ke Jawa Tengah

\begin{tabular}{|l|l|}
\hline Tahun & Jumlah Pengunjung \\
\hline 2014 & 20.271 .679 \\
\hline 2015 & 33.452 .034 \\
\hline
\end{tabular}

Sumber: Badan Pusat Statistik

Keberadaan wali songo ini sangat berpengaruh pada perkembangan agama Islam di Indonesia, khusunya pulau jawa. Kesembilan wali tersebut memiliki kelebihan dari manusia biasa, mereka memilik kharisma, hingga sampai meninggal mereka tetap memiliki kharisma. Bukti dari besarnya kharisma wali songo dapat kita lihat dari bentuk kompleks bangunan makam ke Sembilan wali.Megahnya bangunan makam sehingga mampu menarik banyak orang untuk mengunjungi serta mendoakan para wali.

$$
\text { Tingginya jumlah pengunjung }
$$
Makam Sunan Kalijaga menjadi penyebab terjadinya pergeseran fungsi dan nilai pada makam. Masyarakat sekitar Makam Sunan Kalijaga, mengubah dan menjadikan area sekitar makam menjadi produktifdan bernilai ekonomis. Makam yang seharusnya digunakan sebagai sarana beribadah telah berubah fungsi menjadi tempat pariwisata dengan menawarkan berbagai komoditi dan pelayanan yang dikemas oleh masyarakat sekitar makam

Tabel 1.2

Jumlah Pedagang di pariwisata Islami makam Sunan Kalijaga di Desa Kadilangu Sumber: Kantor Kelurahan Kadilangu

\begin{tabular}{|c|c|}
\hline Nama Paguyuban Pedagang & Jumlah \\
\hline Paguyuban Pedagang kadilangu Demak & 114 orang \\
\hline Warung dan Souvenir & 46 Orang \\
\hline Ronde dan Asongan & 174 Orang \\
\hline Jumlah & 334 Orang \\
\hline Tabel 1.2 dapat menunjukan
\end{tabular}

bahwa pedagang yang berjualan di kawasan makam Sunan Kalijaga di Desa Kdilangu Kabupaten demak, ada tiga type pedagang, yaitu paguyuban pedagang kadilangu demak, Warumg dan Souvenir, ronde dan asongan.

Motif ekonomi menjadi pemicu utama masyarakat sekitar Makam Sunan Kalijaga dalam memanfaatkan dan mengkomersilkan keberadaan makam. Tuntutan kebutuhan hidup mengharuskan masyarakat mempunyai cara untuk mempertahankan kehidupannya, termasuk mengubah sekitar makam menjadi lahan untuk mengais rejeki. Kemajuan pariwisata sangat berkontribusi terhadap pergeseran fungsi dan nilai pada makam. Pada kenyataanya makam membawa manfaat diberbagai bidang, diantaranya dalam bidang budaya, politik dan khususnya dalam bidang sosial ekonomi.

Dampak sosial dari dijadikannya makam menjadi tempat wisata antara lain masyarakat berkesempatan megenali ciri, 
Rahman, et al/Jurnal Ekonomi Syariah Teori dan Terapan Vol. 5 No. 6 Juni 2018: 511-521; PEREKONOMIAN PARIWISATA ISLAMI TERHADAP PEDAGANG DI KAWASAN MAKAM SUNAN KALIJAGA

bahasa dan kebudayaan pengunjung

pendapatan penduduk, manfaat makam. Sedangkan dalam bidang ekonomi keberadaan Makam Sunan Kalijaga juga membawa dampak positif yaitu terjadi peningkatan pendapatan pada masyarakat sekitar makam.

Berdasarkan uraian latar belakang diatas, maka rumusan masalah yang dapat diajukan pada penelitian ini adalahBagaimanakah dampak wisata Islami Sunan Kalijaga terhadap pedagang disekitarnya

\section{LANDASAN PUSTAKA}

Pariwisata berasal dari bahasa sansekerta yang terdiri dari dua suku kata yaitu "pari" dan "wisata". Pari artinya berulang-ulang, sedangkan wisata artinya berpergian. Jadi pariwisata adalah perjalanan yang dilakukan berulangulang (Yoeti, 1987:103)

$$
\text { Menurut Meyers }
$$

Pariwisata adalah kegiatan melakukan perjalanan dengan tujuan mendapatkan kenikmatan, mencari kepuasan, mengetahui sesuatu, memperbaiki kesehatan, menikmati olahraga atau istirahat, menunaikan tugas, berziarah dan lain-lain. Sedangkan menurut Pendit (2002:30) mendefinisikan pariwisata sebagai orang-orang yang berpergian untuk sementara dalam jangka waktu yang pendek ke tempat-tempat tujuan di luar tempat tinggal dan tempat bekerja. Tujuan mereka melakukan perjalanan ke tempat wisata benar-benar sebagai seorang konsumen.

Pariwisata memberikan pengaruh besar pada peningkatan serta 
Rahman, et al/Jurnal Ekonomi Syariah Teori dan Terapan Vol. 5 No. 6 Juni 2018: 511-521; PEREKONOMIAN PARIWISATA ISLAMI TERHADAP PEDAGANG DI KAWASAN MAKAM SUNAN KALIJAGA

diterima sebagai stadart moral dan susila dan juga untuk menghormati kepercayaan lokal serta tradisi dan peduli terhadap lingkungan, ini merupakan pandangan baru tentang kehidupan dan masyarakat.

Wisata religi adalah wisata yang sedikit banyak dikaitkan dengan agama, sejarah, adat istiadat, kepercayaan umat atau kelompok dalam masyarakat.Wisata ini banyak dilakukan perorangan atau rombongan ke tempat-tempat suci, ke makam orang-orang besar atau pemimpin yang diagungkan, ke bukit atau gunumg yang dikeramatkan, ke tempat pemakaman tokoh atau pemimpin sebagai manusia ajaib penuh legenda (Pendit,2002:42)

Kompleks makam Sunan Kalijaga terletak diKelurahan Kadilangu Kecamatan Demak Kabupaten Demak. Di dalam areal kompleks makam ada empat buah bangunan, yaitu bangunan tempat peristirahatan bagi para peziarah, bangunan tempat pendaftaran tamu, bangunan makam Pangeran Wijil ke $\mathrm{V}$ (merupakan cucu dari Sunan Kalijaga),bangunan makam Sunan Kalijaga.

Izzan dan Tanjung (2006:32) berpendapat bahwa ekonomi Islam adalah kumpulan dari dasar-dasar umum ekonomi yang diambil dari Al-Qur'an dan sunnah Rasullah serta tatanan ekonomi yang dibangun diatas dasar-dasar tersebut, sesuai dengan berbagai macam lingkungan dan setiap zaman.

\section{METODE PENELITIAN}

Data yang terkumpul akan dilakukan pengujian secara kualitatif yaitu metode penelitian yang digunakan untuk meneliti kondisi objek dimana peneliti merupakan instrumen kunci, teknik pengumpulan data dilakukan secara triangulasi (gabungan), analisis data, dan hasil penelitian kualitatif lebih mement

Penelitian ini digunakan untuk menjawab rumusan masalah penelitian tentang dampak wisata Islami terhadap pedagang di kawasan Sunan Kalijaga Kabupaten Demak.

\section{Identifikasi Variabel}

Identifikasi variabel dalam rumusan masalah tersebut menjadi acuan peneliti dalam menentukan ruang lingkup penelitian. Ruang lingkup penelitian terbatas pada dampak wisata islami sunan kalijaga terhadap pedagang. Dampak wisata islami sunan kalijaga dari sudut pandang pedagang. Pemilihan pedagang karena pedagang yang paling banyak melakukan aktifitas ekonomi di wisata islami sunan kalijaga. Objek yang di teliti adalah pedagang yang berjualan di kawasan makam Sunan Kalijaga yang berada di desa kadilangu, Demak.

\section{Ruang Lingkup Penelitian}

Rumusan masalah tersebut
menjadi acuan peneliti dalam menentukan ruang lingkup penelitian. Ruang lingkup penelitian terbatas pada dampak wisata islami sunan kalijaga terhadap pedagang. Dampak wisata islami sunan kalijaga dari sudut pandang 
Rahman, et al/Jurnal Ekonomi Syariah Teori dan Terapan Vol. 5 No. 6 Juni 2018: 511-521; PEREKONOMIAN PARIWISATA ISLAMI TERHADAP PEDAGANG DI KAWASAN MAKAM SUNAN KALIJAGA

pedagang. Pemilihan pedagang karena

penelitian. Wawancara (interview) pedagang yang paling banyak melakukan aktifitas ekonomi di wisata islami sunan kalijaga. Objek yang di teliti adalah pedagang yang berjualan di kawasan makam Sunan Kalijaga yang berada di desa kadilangu, Demak.

\section{Teknik Penentuan Informan}

informan adalah untuk menggali informasi yang menjadi dasar dan rancangan teori yang dibangun. Menurut sugiyono (2010:218) teknik penentuan informan dibagi menjadi dua macam, yaitu purposive sampling dan snowball Sampling.

Pengertian snowball sampling adalah proses penentuan informan berdasarkan informan sebelumnya tanpa menentukan jumlahnya secara pasti dengan menggali informasi terkait topik penelitian yang diperlukan. Pencarian informan akan dihentikan setelah informasi penelitian dianggap sudah memadai. Sedangkan Pengertian Purposive sampling adalah teknik pengambilan sampel sumber data dengan pertimbangan tertentu.

\section{Teknik pengumpulan data}

Teknik pengumpulan data yang dipakai dalam penelitian ini menggunakan cara sebagai berikut:

\section{Wawancara}

Wawancara adalah salah satu cara pengumpulan data primer dalam suatu penelitian. Karena menyangkut data, maka wawancara merupakan salah satu elemen penting dalam proses dipergunakan untuk mendapatkan informasi atau data dari responden dengan cara bertanya secara langsung dengan bertatap muka. tetapi, teknik wawancara ini dalam perkembangannya tidak harus dilakukan secara berhadapan langsung (face to face), melainkan dengan memanfaatkan sarana komunikasi lain, misalnya telepon atau internet (Mashud, 2006:69).

\section{Dokumentasi}

Dokumentasi digunakan karena sejumlah besar fakta dan data sosial tersimpan dalam bahan yang berbentuk dokumentasi. Sebagian besar data yang tersedia adalah berbentuk surat-surat, catatan harian, cendera mata, laporan, dan sebagainya (Bungin, 2009:121-122).

\section{Observasi}

Observasi atau disebut juga pengamatan adalah kegiatan terhadap suatu obyek dengan menggunakan seluruh alat indra dan dilaksanakan secara langsung. Penelitian observasi dapat dilakukan dengan tes,kuesioner, rekaman gambar, rekaman suara (Arikunto 2006:156-157).

Sejarah Perdagangan di kawasan Pariwisata Islami Sunan Kalijaga di Kabupaten Demak

Seiring berjalannya waktu kawasan makam Sunan kalijaga semakin berkembang, berkembangnya pedagang disebabkan karena semakin banyaknya peziarah yang mengunjungi kompleks pariwisata Islami Sunan Kalijaga dari tahun 
Rahman, et al/Jurnal Ekonomi Syariah Teori dan Terapan Vol. 5 No. 6 Juni 2018: 511-521; PEREKONOMIAN PARIWISATA ISLAMI TERHADAP PEDAGANG DI KAWASAN MAKAM SUNAN KALIJAGA

ke tahun. Akhirnya para pedagang membuka kios-kios sederhana di kawasan yang dulunya belum dibangun kios. Produk yang di tawarkan juga beraneka ragam mulai dari makanan tradisional khas Demak, buah-buahan, tasbih, sajadah,Pernak-pernik dan masih banyak lagi. Hal tersebut adalah gambaran bahwa kebutuhan peziarah dapat diperoleh di pedagang kios yang berada di sekitar kawan makam Sunan Kalijaga Kabupaten Demak.

\section{Potensi Pengunjung}

Wisatawan yang berkunjung ke pariwisata Islami Sunan Kalijaga di Kabupaten Demakmenunjukkan bahwa sekitar $47 \%$ berasal dari luar Jawa Tengah. Tujuannya bermacam macam antara lain ada yang untuk berziarah ke keluarga yang dimakamkan di pemakaman kadilangu, ada juga yang mengikuti kegiatan tour Wali Songo yang bertujuan untuk mendoakan Para Wali.

Wisatawan juga di dominasi oleh laki-laki dengan tingkat persentase sebesar $72 \%$ yang melakukan kunjungan ke pariwisata Islami makam Sunan Kalijaga di Kabupaten Demak dan wisatawan yang mendominasi adalah wisatawan yang memiliki pekerjaan swasta, dengan persentase sebesar $43 \%$. Berdasarkan Pendapatan, wisatawan di kawasan makam Sunan Kalijaga Kabupaten Demak memiliki rata-rata pendapatan $\operatorname{Rp} 2.000 .000$ - Rp 3.000 .000 dengan persentase $36 \%$.

IV. HASIL PENELITIAN DAN PEMBAHASAN
Berdasarkan hasil wawancara terhadap pedagang yang datanya dapat dilihat lampiran 3, bahwa rata-rata pedagang adalah warga asli Demak, tetapi tidak seluruhnya pedagang asli dari kabupaten demak. Dalam wawancara singkat para pedagang yang bukan warga asli demak, mereka adalah warga luar yang menikah dengan orang Desa Kadilangu Kabupaten demak dan akhirnya berjualan di kawasan pariwisata Islami Sunan kalijaga di kabupaten Demak. Kejadian tersebut dapat menunjukkan bahwa Pariwisata Islami Makam Sunan Kalijaga di kabupaten Demak mempunyai peranan penting dalam meningkatkan keadaan perekonomian masyarakat yang ada di sekitarnya. Selain itu, usia bisnis pedagang yang telah menjadi informan pada penelitian ini lebih dari dua tahun. Hal tersebut menunjukkan bahwa berdagang di lokasi pariwisata Islami makam Sunan Kalijaga di Desa Kadilangu Kabupaten Demak adalah bisnis yang terus bertahan sampai saat ini.

\section{Tabel 4.1}

Jumlah dan Jenis usaha di kawasan Pariwisata Islami makam Sunan Kalijaga Kabupaten demak

\begin{tabular}{|c|c|c|c|c|}
\hline No & Jenis Usaha & Jumlah & Persentase & Jumlah Informan \\
\hline 1 & Souvenir & 75 & $76 \%$ & 9 \\
\hline 2 & Makanan dan minuman & 23 & $24 \%$ & 6 \\
\hline & Total & 98 toko & $100 \%$ & 15 toko \\
\hline
\end{tabular}

Tabel tersebut memperlihatkan bahwa jenis usaha di kawasan pariwisata Islami makam Sunan Kalijaga di Desa Kadilangu Kabupaten Demak didominasi oleh pedagang souvenir sebesar $76 \%$, 
Rahman, et al/Jurnal Ekonomi Syariah Teori dan Terapan Vol. 5 No. 6 Juni 2018: 511-521; PEREKONOMIAN PARIWISATA ISLAMI TERHADAP PEDAGANG DI KAWASAN MAKAM SUNAN KALIJAGA

sedangkan pedagang makanan dan

hasil wawancara dilapangan dimana minuman mempunyai persentase sebesar 24\%. Dari hasil observasi peneliti, penyebab para pedagang berdagang di kawasan makam Sunan Kalijaga karena dekatnya tempat mereka berdagang dengan tempat tinggal mereka serta dengan adanya wisatawan yang secara langsung terjadi perputaran ekonomi yang terjadi dengan cara jual beli.

Hasil wawancara kepada pedagang menunjukkan bahwa rata-rata usaha di lokasi pariwisata adalah sumber pendapatan utama, tetapi ada lima pedagang yang memiliki usaha lain di luar kawasan pariwisata Islami makam Sunan Kalijaga. Hasil wawancara dengan 15 pedagang, hanya satu yang memiliki tenaga kerja dan lainnya memiliki teaga kerja hanya sebagai penjaga kios. Hal tersebut dapat diartikan bawa adanya pariwisata Islami makam Sunan Kalijaga ini dapat menciptakan lapangan pekerjaan bagi masyarakat sekitar. Berikut adalah tabel rata-rata pendapatan bersih yang diterima oleh pedagang.

Tabel 4.2

Rata-rata pendapatan bersih pedagang

\begin{tabular}{|c|c|c|}
\hline No & Jenis Usaha & $\begin{array}{c}\text { Rata-rata pendapatan bersih } \\
\text { (perbulan) }\end{array}$ \\
\hline 1 & Souvenir & $\mathrm{Rp} 2.500 .000$ \\
\hline 2 & Makanan dan minuman & $\mathrm{Rp} 1.700 .000$ \\
\hline
\end{tabular}

Tabel 4.2 menunjukkan bahwa pendapatan bersih rata-rata pedagang dalam waktu satu bulan pada informan adalah pada pedagang souvenir, sebesar Rp 2.500.000. hal tersebut sesuai dengan besar daripada pedagang makanan dan minuman.

\section{Tenaga kerja}

Dari ramainya pengunjung obyek pariwisata Islami makam Sunan Kalijaga, dapat menciptakan lapangan pekerjaan yang memberdayakan masyarakat sekitar dengan cara melibatkan langsung dalam kegiatan perekonomian. Kegiatan tersebut diantaranya adalah terciptanya lapangan kerja dan peluang untuk melakukan bisnis atau berdagang yang berkaitan erat dengan kebutuhan wisatawan di kawasan pariwisata Islami makam Sunan Kalijaga

Tenaga kerja yang berada di lokasi pariwisata Islami makam Sunan Kalijaga ini telah bekerja selama 6 bulan-3 tahun. Pendapatan perbulan yang diperoleh oleh tenaga kerja di lokasi makam Sunan kalijaga berkisar antara Rp 350.000Rp550.000 dengan jam kerja 5-6 jam per harinya. Dari keterangan tersebut, apabila dilihat dari keuntungan pedagang, upah yang diterima tenaga kerja masih terlalu kecil, dan apabila dibandingkan dengan UMK Kabupaten demak, upah tersebut sangat jauh dibawah UMK.

Wawancara yang dilakukan pada Tenaga kerja, dapat disimpulkan bahwa semua tenaga kerja tidak merasa terganggu dengan adanya pariwisata Islami makam Sunan Kalijaga di Desa Kadilangu Kabupaten Demak ini, bahkan 
Rahman, et al/Jurnal Ekonomi Syariah Teori dan Terapan Vol. 5 No. 6 Juni 2018: 511-521; PEREKONOMIAN PARIWISATA ISLAMI TERHADAP PEDAGANG DI KAWASAN MAKAM SUNAN KALIJAGA

semua tenaga kerja merasakan manfaat adanya pariwisata Islami tersebut. Manfaat yang dirasakan oleh tenaga kerja antara lain:

1. Meningkatnya pendapatan. Dimana adanya tambahan pendapatan atau penghasilan dari adanya pariwisata Islami makam Sunan kalijaga di Desa Kadilangu Kabupaten Demak ini. Tenaga kerja mendapatkan esempatan memperoleh vang dengan bekerja.

2. Peningkatan tenaga kerja. Semakin ramainya wisatawan yang datang, semakin banyak juga tenaga kerja maupun pedagang yang melakukan kegiatan ekonomi. Semakin ramai wisatawan membeli dagangan pedagang, dampaknya juga akan dirasakan tenaga kerja yaitu semakin bertambahnya kebutuhan akan tenaga kerja.

Peningkatan Lapangan Kerja. Dengan adanya pariwisata Islami makam Sunan Kalijaga di Desa Kadilangu Kabupaten Demak, semakin banyak peluang untuk membuka usaha dan semakin banyak juga membuka lapangan pekerjaan bagi masyarakat yang ada di sekitarnya

Dinamisasi Perekonomian Pariwisata Islami Terhadap Pedagang Kios di Kawasan Makam Sunan Kalijaga Kabupaten Demak

Dinamisasi perekonomian dari kegiatan pariwisata merupakan dinamisasi mendasar yang ditimbulkan oleh kegiatan tersebut terhadap kondisi masyarakat mengenai peningkatan dan penurunan pendapat yang dirasakan oleh masyarakat, perluasan lapangan pekerjaan dan perilaku setiap masyarakat kepada lingkungan yang ada di sekitarnya.

Ketika pengunjung mengeluarkan sejumlah uang untuk melakukan pembelian kepada produk dan jasa di lokasi pariwisata, pada akhirnya pengunjung tersebut memberikan perubahan terhadap penghasilan pendapatan bagi pedagang yang ada di lokasi pariwisata tersebut dan juga memberikan perubahan penghasilan kepada tenaga kerja yang berada di lokasi pariwisata tersebut. Andai saja pemerintah melakukan upaya menambah perlengkapan sarana prasarana yang lebih memadai serta promosi yang lebih efektif maka akan memperluas kesempatan kerja maupun peningkatan pendapatan para pedagang dan tenaga kerja yang berada di lokasi pariwisata tersebut. Perubahan perekonomian yang dihasilkan dari sektor pariwisata umumnya diukur dari keseluruhan pengeluaran wisatawan untuk keperluan transportasi, makanan, minuman dan keperluan lainnya. Jumlah dari keseluruhan pengeluaran tersebut muadian di estimasi dari pengeluaran yang dikeluarkan oleh wisatawan.

Dinamisasi Perekonomian Ditinjau dari Wisatawan 
Rahman, et al/Jurnal Ekonomi Syariah Teori dan Terapan Vol. 5 No. 6 Juni 2018: 511-521; PEREKONOMIAN PARIWISATA ISLAMI TERHADAP PEDAGANG DI KAWASAN MAKAM SUNAN KALIJAGA

Wisatawan dalam melakukan perjalanan pariwisata membutuhkan berbagai kebutuhan diantaranya kebutuhan transportasi, makanan, minuman, dokumentasi, souvenir dan kebutuhan lainnya. Apabila dari aneka ragam kebutuhan wisatawan tersebut dipenuhi oleh para pedagang, maka akan terjadi aktifitas ekonomi antara pedagang dan wisatawan. Sehingga terjadi perputaran uang pada luar obyek pariwisata ke dalam obyek pariwisata. Dan apabila kejadian tersebut terjadi secara terus menerus maka kan menguntungkan para pedagang di lokasi pariwisata tersebut.Dinamisasi perekonomian dari kegiatan pariwisata di obyek pariwisata Islami makam Sunan Kalijaga Desa Kadilangu di Kabupaten Demak karena adanya perputaran vang yang berasal dari pembelian barang dari wisatawan kepada pedagang di kawasan pariwisata Islami makam Sunan Kalijaga di Desa Kadilangu di Kabupaten Demak.

\section{Tabel 4.3}

\section{Persentase Pengeluaran Wisatawan}

\begin{tabular}{|c|c|c|c|}
\hline No & Jenis Biaya & Jumlah & Persentase \\
\hline 1 & Transportasi & $\mathrm{Rp} 3.285 .000$ & $49 \%$ \\
\hline 2 & Konsumsi & Rp 1.529.500 & $23 \%$ \\
\hline 3 & Souvenir & Rp 1.974.000 & $28 \%$ \\
\hline & Total & Rp 6.788.500 & $100 \%$ \\
\hline \multicolumn{4}{|c|}{$\begin{array}{l}\text { Hasil wawancara dengan } 14 \text { wisatawan. } \\
\text { Sumber: Data Primer diolah oleh penulis }\end{array}$} \\
\hline & Hasil & awancara & dengan \\
\hline
\end{tabular}

wisatawan yang menjadi informan dalam penelitian ini, persentase pengeluaran wisatawan di kawasan pariwisata Islami makam Sunan Kalijaga di Desa Kadilangu di Kabupaten Demak dapat dilihat pada tabel 4.8. Di dalam tabel tersebut menunjukkan bahwa persentase pengelvaran wisatawan paling banyak digunakan untuk mengeluarkan biaya transportasi. Rata-rata pengeluaran wisatawan untuk sekali melakukan kunjungan memerlukan biata transportasi Rp 15.000-Rp 600.000. hal tersebut dipengaruhi oleh beberapa faktor, antara lain daerah asal, jumlah rombongan, aktifitas yang dilakukan di lokasi pariwisata dan jumlah tujuan pariwisata lain selama perjalanan.

\section{Dinamisi Perekonomian Ditinjau dariTenaga Kerja}

Adanya obyek pariwisata Islami makam Sunan Kalijaga di Desa Kadilangu Kabupaten Demak membuka kesempatan kerja dan peluang usaha bagi masyarakar sekitar obyek pariwisata. Dari hasil observasi di kios pedagang, ada kios yang tetap dijaga dan dikelola pemiliknya, ada pula kios yang di jaga oleh tenaga kerja.

Tenaga Kerja di kawasan objek pariwisata Islami makam Sunan kalijaga di Desa Kadilangu di Kabupaten Demak rata-rata adalah masyarakat sekitar kawasan pariwisata Islami makam Sunan kalijaga di Desa Kadilangu di Kabupaten Demak. Hal tersebut dikarenakan salah satu tujuan adanya obyek pariwisata adalah pemberdayaan serta membuka lapangan kerja untuk warga masyarakat sekitar lokasi pariwisata. Dimana tenaga 
Rahman, et al/Jurnal Ekonomi Syariah Teori dan Terapan Vol. 5 No. 6 Juni 2018: 511-521; PEREKONOMIAN PARIWISATA ISLAMI TERHADAP PEDAGANG DI KAWASAN MAKAM SUNAN KALIJAGA

kerja merupakan pihak yang secara tidak langsung merasakan perubahan perekonomian dari adanya pariwisata tersebut, yakni melalui pendapatan yang mereka terima dari pedagang. Berikut adalah hasil wawancara dengan tenaga kerja mengenai jenis dan jumlah pengeluaran yang dilakukan oleh tenaga kerja

Tabel 4.4

\begin{tabular}{|l|l|c|c|}
\hline No & Jenis Pengeluaran & Jumlah Pengeluaran (Rp) & Persentase \\
\hline 1 & Kebutuhan sehari-hari & Rp 1.835 .000 & $89,08 \%$ \\
\hline 2 & Transportasi & Rp 225.000 & $10,92 \%$ \\
\hline \multicolumn{2}{|c|}{ Total } & Rp 2.060.000 & $100 \%$ \\
\hline
\end{tabular}

Jenis dan Jumlah Pengeluaran Tenaga Kerja

Dari tabel 4.4 dapat dilihat bahwa sebagian besar pengeluaran tenaga kerja digunakan untuk kebutuhan sehari-hari sebesar $89,08 \%$, sedangkan sisanya untuk transportasi sebesar 10,92\%. Kebutuhan sehari-hari tenaga kerja masih tergolong cukup tinggi, namun dari gaji yang tidak sepadan dengan jam mereka bekerja. Harusnya pedagang memberikan gaji yang selayaknya untuk tenaga kerja agar kebutuhan tenaga kerja terpenuhi dan juga agar pedagang dipandang berlaku adil atau tidak dzalim kepada tenaga kerja.

\section{SIMPULAN}

Berdasarkan hasil diatas dapat ditarik kesimpulan bahwa Allah SWT mendorong manusia untuk melakukan perjalanan atau berpergian dalam proses hidupnya, agar memperluas ilmu dan wawasan serta dapat melihat kebesaran dan keagungan ciptaan Allah SWT dengan nyata, sehingga makhluk ciptaan Allah SWT dapat meningkatkan keimanan dan ketaqwaan Kepada Allah SWT.

Keberadaan Pariwisata Islami makam Sunan Kalijaga memberikan dampak ekonomi bagi masyarakat sekitar. Dampak ekonomi tersebut berupa pendapatan dari pemilik kios yang berasal dari wisatawan yang mengeluarkan pengeluaran untuk membeli souvenir di tempat pariwisata tersebut. Selain itu dampak ekonomi juga dirasakan oleh Tenaga Kerja karena semakin ramainya tempat wisata tersebut, daya beli wisatawan juga semakin naik. Rata-Rata mereka membeli souvenir untuk cinderamata, makanan dan minuman untuk di konsumsi seusai melakukan ziarah dan konveksi untuk kenang-kenangan dari Kawasan Makam Sunan Kalijaga

\section{DAFTAR PUSTAKA}

Ahmad Izzan, dan Syahri Tanjung. 2006. Referensi Ekonomi Syariah; ayatayat Al-Qur'an yang berdimensi ekonomi. Bandung: PT. Remaja Rosdakarya. Cet.1.

Arikunto, Suharsimi. 2006. Prosedur Penelitian Suatu Pendekatan Praktik.Jakarta :Rineka Cipta.

Bungin, Burhan. 2009. Penelitian Kualitatif. Jakarta: Prenada Media Group

I Gede Pitana dan Putu G. Gayatri. 2007. Sosiologi pariwisata. Yogyakarta: Andi. 
Rahman, et al/Jurnal Ekonomi Syariah Teori dan Terapan Vol. 5 No. 6 Juni 2018: 511-521; PEREKONOMIAN PARIWISATA ISLAMI TERHADAP PEDAGANG DI KAWASAN MAKAM SUNAN KALIJAGA

Mashud, Musta'in. 2006. Metode

Penelitian Sosial. Jakarta: Kencana

Prenada Media Group.

Meyers, Koen. 2009. Panduan Dasar

Pelaksanaan Ekowisata. Jakarta: Unesco Office.

Nyoman S. Pendit. 2002. IImu Pariwisata Sebuah Pengantar. Jakarta : Pradnya Paramita.

Sugiyono, 2010. Metode Penelitian Kuantitatif Kualitatif \& RND. Bandung: Alfabeta.

Yoeti, Oka A. 1987. Pengantar IImu

Pariwisata. Bandung: Angkasa.

http://m.tempo.co/read/news/2015/04/05 / 1 16655429/4-sebab-islam-jadi-agamaterbesar-dunia-pada-2070 (di akses pada 28 Oktober 2016) 